\title{
UM NOVO MODELO DE RACIOCÍNIO PRÁTICO COMO UMA POSSÍVEL RESPOSTA AO FENÔMENO DO MULTICULTURALISMO EM CHARLES TAYLOR
}

\author{
A new model of practical reasoning as a possible way to respond to the phenomenon of \\ multiculturalism in Charles Taylor
}

\author{
Caroline Ferreira Fernandes*
}

Resumo: Nosso escopo fundamental nesse trabalho é mostrar que o modelo de razão prática proposto por Charles Taylor é um possível caminho para responder ao problema do multiculturalismo contemporâneo. Problema esse que tem se mostrado urgente nos tempos atuais e sido alvo de uma vasta literatura, sendo muitas delas ambivalentes. Nessa perspectiva, nosso esforço nesse artigo será mostrar que o caminho hermenêutico de racionalidade prática é capaz de promover um desenvolvimento autêntico de reconhecimento entre pessoas e culturas. $\mathrm{O}$ trabalho está dividido em três partes fundamentais: A primeira parte mostrará as inadequações do modelo desprendido de razão prática moderna que temos vivido na modernidade. Na segunda parte, mostraremos como Taylor desenvolve um novo modelo de razão prática sem critérios preestabelecidos em disputas morais. Na terceira e última parte, evidenciaremos a nossa tese de que essa noção de razão prática que culmina em uma política do reconhecimento pode ser um caminho para lidarmos com o problema do multiculturalismo sem cairmos em um relativismo moral.

Palavras-chave: Charles Taylor. Razão prática. Reconhecimento. Multiculturalismo.

\begin{abstract}
Our fundamental purpose in this article is to show that the model of practical reason proposed by Charles Taylor is a possible way to respond to the contemporary problem of multiculturalism. This problem has been seen as urgent in current times and it has been subject of a range of literature, many of which are ambivalent. In this perspective, our effort in this article will be to show that a hermeneutic way of practical rationality is able to promote an authentic development of recognition between people and cultures. The text is divided into three main parts: The first part will show the inadequacies of the disengaged model of modern practical reason that we have lived in the modernity. In the second part, we'll show how Taylor develops a new model of practical reason without pre-established criteria in moral dilemmas. In the third and final section, we will highlight our thesis that this notion of practical reason, which culminates in politics of recognition, can be a way to deal with the problem of multiculturalism without falling into moral relativism.
\end{abstract}

Keywords: Charles Taylor. Practical reason. Recognition. Multiculturalism.

\footnotetext{
* Mestranda em Filosofia pela Faculdade Jesuíta de Filosofia e Teologia (FAJE). Bolsista CAPES. Contato: carol_thiff@hotmail.com
}

\begin{tabular}{|c|c|c|c|c|c|}
\hline intuitio & $\begin{array}{c}\text { ISSN } \\
1983-4012\end{array}$ & Porto Alegre & Vol.7 - No.1 & $\begin{array}{c}\text { Junho } \\
2014\end{array}$ & p.200-214 \\
\hline
\end{tabular}




\section{Introdução}

A ideia fundamental que norteia o nosso trabalho e que tentaremos dar um possível norte ao longo do texto diz respeito à possibilidade de se estabelecer um diálogo entre culturas, reconhecendo cada uma em sua identidade e diferença, sem escorregarmos para um relativismo moral ou para um etnocentrismo sem precedentes. Estamos cientes de que vivemos em um mundo plural seja em relação às religiões, aos discursos éticos, aos embates políticos ou às culturas. O fato é que há um relativismo e ceticismo morais latentes em nossa civilização, desde que reconhecemos a fragilidade do discurso racional em relação às coisas humanas. O que era reino do quase sempre em Aristóteles e fruto de uma teoria ética, deu lugar a um sentimento de desorientação moral e espiritual, marcas de um período em crise como o nosso em que a proliferação de teorias éticas não têm resolvido nem norteado a concretude dos nossos dilemas morais, principalmente aqueles que dizem respeito ao debate intercultural.

Nessa perspectiva, acreditamos que o atual cenário ético não só tem produzido essa crise espiritual, mas também tem provocado uma grande desorientação dos indivíduos acerca da diversidade de bens, do usufruto da sua própria autonomia e da busca por um bem digno de nossa atenção e de nosso apreço. Partindo, portanto, desse momento de ruptura com o saber ético vigente, acreditamos ser possível responder aos fenômenos característicos do nosso tempo com uma concepção renovada de self, que não seja desengajado e desencarnado, como proposto pela tradição epistemológica moderna, mas sim engajado e corporificado.

Para explicar essa concepção de self, Taylor partirá de uma análise profunda da construção da identidade moderna, buscando superar a noção de desengajamento proposta pela epistemologia moderna que, na perspectiva dele, tem sido fonte de distorções do nosso raciocínio moral. É sobre esse ponto que falaremos na primeira parte do nosso texto, no intuito de evidenciar que a razão prática moderna foi estruturada tendo como base uma visão naturalista do homem e que os modelos de raciocínio prático que dela sucederam podem ser considerados profundamente reducionistas, ou melhor, distorções do nosso raciocínio moral. Nesse sentido, pode-se dizer que a busca incessante de Taylor por compreender o seu tempo o levou a perscrutar sobre as raízes dos problemas que enfrentamos hoje, no intuito de resgatar e suprassumir valores que a modernidade tentou solapar, propondo uma ontologia moral mais rica do que aquela proposta pela epistemologia moderna.

Sendo assim, a proposta de Taylor pelo resgate da noção de ontologia moral dar-se-á por uma concepção fundamental que alicerça a ideia de raciocínio prático, a de que somos agentes morais que se estruturam narrativa e livremente de acordo com as nossas avaliações fortes e as

\begin{tabular}{|c|c|c|c|c|c|}
\hline intuitio & $\begin{array}{c}\text { ISSN } \\
1983-4012\end{array}$ & Porto Alegre & Vol.7 - $\mathrm{N}^{\circ} .1$ & $\begin{array}{l}\text { Junho } \\
2014\end{array}$ & p.200-214 \\
\hline
\end{tabular}


Um novo modelo de raciocínio prático como uma possível resposta ao fenômeno do multiculturalismo em Charles Taylor escolhas pelos nossos bens de vida. Essa ontologia moral constitui o que Taylor chama de pano de fundo que estrutura as nossas intuições morais. Segundo ele, "há um quadro de nossa natureza e condição espiritual que dá sentido à nossas respostas" ", há um pano de fundo moral que mostra a melhor maneira que devemos viver, que vida realmente vale a pena ser vivida. É por esse viés que o nosso filósofo caminha e que caminharemos nesse artigo, propondo um novo olhar sobre as questões morais e sobre o próprio self.

Nesse sentido, o fenômeno em questão, o multiculturalismo, torna-se um problema evidente nesse cenário de pluralismo de discursos éticos, afinal reconhecer o outro como um verdadeiro agente moral respeitando sua igualdade em relação aos outros seres humanos, mas também suas diferenças, torna-se o problema crucial de uma proposta de ontologia moral que se sustente. Afinal, o tema do reconhecimento tem sido tratado como um problema antropológico e não uma questão extra opcional. Segundo Taylor, "qualquer explicação adequada deve fazer justiça tanto a diferença quanto a unidade" ${ }^{2}$ e o seu intuito "é contribuir com uma compreensão plausível de raciocínio moral que reflita tanto sua iniludível diversidade como sua luta constante pela unidade" 3 .

Sendo assim, a nossa proposta por defender um raciocínio prático faz-se necessária diante do debate contínuo de questões éticas na academia, pelo visível ceticismo e relativismo morais existentes, pela necessidade de mostrar que os problemas éticos são antes de tudo questões que dizem respeito à humanidade como um todo e, principalmente, pela necessidade de situar o problema do multiculturalismo no cenário ético-político atual a partir de uma concepção renovada de razão prática, indivíduo e sociedade.

Na primeira parte do texto, intentamos mostrar em linhas gerais um breve percurso do irrompimento da epistemologia moderna como base para a estruturação dos modelos de raciocínio prático modernos. Nossa intenção é evidenciar as críticas que Taylor faz a dois modelos surgidos a partir do modelo de validação racional próprios desse cânone da epistemologia, a saber, utilitarismo e formalismo. Taylor criticará esses dois modelos como os extremos fundamentais da filosofia moral moderna, pois deles sucederam outras vertentes. Por isso a necessidade de explicitação dessa crítica, principalmente pelo fato de serem frutos de uma teoria do conhecimento de base e da intenção subjacente de transpor o sucesso das ciências para o campo das ciências humanas, que segundo Taylor, constitui um dos maiores equívocos da nossa

${ }^{1}$ TAYLOR, Charles. As Fontes do Self: a construção da identidade moderna. $3^{\mathrm{a}}$. ed. São Paulo: Loyola, 2011, p. 22.

${ }^{2}$ TAYLOR, Charles. La Libertad de los modernos. Buenos Aires: Amorrortu, 2005, p. 284. (Tradução nossa)

${ }^{3}$ Cf. TAYLOR, Charles. La Libertad de los modernos. Buenos Aires: Amorrortu, 2005, p. 284. (Tradução nossa)

\begin{tabular}{|c|c|l|l|l|l|}
\hline intuitio & $\begin{array}{c}\text { ISSN } \\
1983-4012\end{array}$ & Porto Alegre & Vol.7 $-\mathrm{N}^{\circ} .1$ & $\begin{array}{c}\text { Junho } \\
2014\end{array}$ & p.200-214 \\
\hline
\end{tabular}


Um novo modelo de raciocínio prático como uma possível resposta ao fenômeno do multiculturalismo em Charles Taylor era. Segundo ele, "estas duas posições extremas ignoram características cruciais e inegáveis de nossa vida moral" ${ }^{4}$. Nossa intenção, portanto, será fazer um "ensaio de resgate" ${ }^{5}$.

A segunda parte do texto ater-se-á ao modelo de raciocínio prático desenvolvido por Taylor a partir das noções fundamentais de avaliações fortes e hiperbens, conceitos caros ao seu pensamento. Mostraremos que o modelo proposto por Taylor pode realmente ser um dos possíveis caminhos para estabelecer um acordo entre os participantes envolvidos em problemas normativos, pois este modelo parte de algum lugar e considera os termos avaliativos fortes.

A terceira e última parte abrirá uma breve discussão acerca do problema dos debates interculturais, buscando entender que o maior obstáculo para uma verdadeira política do reconhecimento se dá por uma visão distorcida e etnocêntrica da racionalidade. Nosso intuito, portanto, será de crítica e de reconstrução para adentrarmos em um rico debate contemporâneo acerca do fenômeno do multiculturalismo sem, contudo, escorregarmos para um relativismo, subjetivismo e ceticismo morais.

\section{A estruturação da razão pratica moderna: As deficiências dos modelos éticos vigentes}

Estamos cientes de que a modernidade é marcada por uma virada reflexiva fundamental em que a busca pela possibilidade e a discussão acerca da origem do conhecimento passou a ter primazia inegável no campo da filosofia. Devido ao afã da ciência moderna que se viu impactada por uma racionalidade procedimental, neutra e desengajada, que poderia gerar promessas de certeza e verdade em tudo aquilo que ela se habilitava pesquisar.

Nesse novo estágio da razão, "a reflexão filosófica tinha por objeto a validade das reivindicações de conhecimento"6, essa era a única serventia da filosofia cujo centro era sua teoria do conhecimento7. "A esta filosofia que pergunta pelo indivíduo e seus processos de conhecimento, antes do que pelas coisas e sua realidade, Taylor chama de tradição epistemológica" ${ }^{\text {. }}$.

\footnotetext{
${ }^{4}$ Cf. TAYLOR, Charles. La Libertad de los modernos. Buenos Aires: Amorrortu, 2005, p. 284. (Tradução nossa)

${ }^{5}$ TAYLOR, Charles. As Fontes do Self: a construção da identidade moderna. $3^{\mathrm{a}}$. ed. São Paulo: Loyola, 2011, p. 23.

${ }^{6}$ TAYLOR, Charles. Superar a epistemologia. Argumentos filosóficos. São Paulo: Loyola, 2000, p. 13.

${ }^{7}$ Richard Rorty diz que "a consequente demarcação da filosofia em relação à ciência foi tornada possível pela noção de que o cerne da filosofia era a 'teoria do conhecimento', uma teoria distinta das ciências porque era seu fundamento". (RORTY, Richard. A filosofia e o espelho da natureza. Rio de Janeiro: Relume Dumará, 1995, p. 140).

${ }^{8}$ FIERRO VALBUENA, Alejandra. Epistemología moderna y ciencias sociales. Un análisis crítico de Charles Taylor. Pensamiento y cultura, Vol. 11, Núm. 2, diciembre-sin mes, 2008, pp. 281-301. Universidad de La Sabana Colombia, p. 284. (Tradução nossa)
}

\begin{tabular}{|c|c|l|l|l|l|}
\hline intuitio & $\begin{array}{c}\text { ISSN } \\
1983-4012\end{array}$ & Porto Alegre & Vol.7 $-\mathrm{N}^{\mathrm{o}} .1$ & $\begin{array}{c}\text { Junho } \\
2014\end{array}$ & p.200-214 \\
\hline
\end{tabular}


Um novo modelo de raciocínio prático como uma possível resposta ao fenômeno do multiculturalismo em Charles Taylor

Torna-se cada vez mais evidente que um novo caminho para a razão prática foi traçado com essa virada reflexiva moderna. Taylor salienta que "em relação à ética, dois modelos de pensamento foram especialmente beneficiados pela influência do modelo de validação subjacente": O utilitarismo que tem marcado as nossas condutas morais com a noção de cálculos racionais/formais acerca da felicidade, e o Formalismo que "tem o aparente valor que eles nos permitiriam ignorar as distinções problemáticas entre diferentes qualidades da ação ou modos de vida"10.

Em relação ao utilitarismo, pautado nos cânones da validação racional, podemos dizer que há uma nova concepção de felicidade humana, não avaliamos mais fortemente, mas sim fracamente. Isso significa deixar de lado as nossas distinções qualitativas sobre o bem viver para uma avaliação do maior benefício e dos prazeres proporcionados pela ação, concebida por ele, a partir de Harry Frankfurt ${ }^{11}$, de avaliações fracas. Esse modo de conceber as ações morais deve-se à tentativa de compatibilizar o discurso ético com a ciência moderna. A felicidade humana passou a estar pautada em cálculos formais ${ }^{12}$, ela "revelou ser algo conceptualmente isento de problemas, um domínio estabelecido cientificamente de fatos como outros"13. Esse discurso é nosso alvo de críticas devido à tentativa de dar primazia aos cálculos formais àquilo que é inegavelmente incalculável. Sendo, na visão de Taylor, profundamente interpretável, avaliável qualitativamente.

Além do mais, o abandono aos fatores metafísicos e teleológicos, levou-nos a um descrédito ao que chamamos de ontologia moral, as peculiaridades humanas foram sendo deixadas de lado pela influência de um naturalismo subjacente à cultura intelectual moderna. Com os utilitaristas, "nós temos o modelo de um ser humano que é clarividente sobre seus objetivos e capaz de objetificar e entender ele mesmo e o mundo em torno dele" ${ }^{14}$. Esse modelo de razão prática tão comum aos nossos dias foi alvo de duras críticas e de descrédito por vários pensadores, entre eles está Kant, situado num extremo oposto, mas também pautado pela tentativa de conceder ao discurso prático um terreno firme como nas ciências.

\footnotetext{
${ }^{9}$ TAYLOR, Charles. The diversity of goods, in Philosophy and the human sciences - Philosophical papers 2. Cambridge: Cambridge University Press, 1985, p. 231. (Tradução nossa)

${ }^{10}$ Cf. TAYLOR, Charles. The diversity of goods, in Philosophy and the human sciences - Philosophical papers 2. Cambridge: Cambridge University Press, 1985, p. 231. (Tradução nossa)

${ }^{11} \mathrm{O}$ texto em que Taylor se baseia de Harry Frankfurt intitula-se "Freedom of the will and the concept of a person", in The Journal of Philosophy, Vol. 68. N. 1 (1971), pp. 5-20.

12 "Essa revelação, afirmo eu, vem das profundezas de nossa cultura moderna e do modelo epistemológico nela ancorado, cuja força se baseia não apenas na afinidade com a ciência mecanicista como em sua congruência com o potente ideal da certeza reflexiva, autofornecida". (TAYLOR, Charles. Superar a epistemologia. Argumentos filosóficos. São Paulo: Loyola, 2000, p. 18)

${ }^{13}$ TAYLOR, Charles. The diversity of goods, in Philosophy and the human sciences - Philosophical papers 2. Cambridge: Cambridge University Press, 1985, p. 230. (Tradução nossa)

${ }^{14}$ Cf. TAYLOR, Charles. The diversity of goods, in Philosophy and the human sciences - Philosophical papers 2. Cambridge: Cambridge University Press, 1985 p. 235. (Tradução nossa)
}

\begin{tabular}{|c|c|c|c|c|c|}
\hline intuitio & $\begin{array}{c}\text { ISSN } \\
1983-4012\end{array}$ & Porto Alegre & Vol.7 - $\mathrm{N}^{\mathrm{o}} .1$ & $\begin{array}{l}\text { Junho } \\
2014\end{array}$ & p. $200-214$ \\
\hline
\end{tabular}


Quanto ao formalismo, Taylor o concebe como a tentativa de abstrair todas as distinções qualitativas do ser humano para a designação de seu valor moral. Afinal, a filosofia moral kantiana ao se basear em um pressuposto fundamental de que só tem valor moral as ações realizadas intencionalmente pelo dever, cuja motivação incondicional é o respeito pela lei moral, ou seja, as ações guidas pelo imperativo categórico e não pelos hipotéticos, tem se mostrado implacável quanto à afirmação de que há bens mais elevados e que nos impulsiona a viver dignamente, sendo relutante mais ainda quanto ao atributo moral desses bens e das intenções dessas avaliações qualitativas. O que nos importa dizer aqui é quais são as "distorções", nas palavras de Taylor, que esses formalismos dos critérios morais nos dão do nosso próprio entendimento do pensamento moral contemporâneo. Taylor define o formalismo como tendo:

o aparente valor que eles nos permitiriam ignorar as distinções problemáticas entre diferentes qualidades de ação ou modos de vida, que desempenham um grande papel em nossas reais decisões morais, sentimentos de admiração, remorso, etc., mas que são tão difíceis de justificar quando outros as contradizem. Eles oferecem a esperança de decidir questões éticas sem ter de determinar quais de um número de linguagens rivais de virtude e vício moral, do admirável ou do desprezível, do incondicional versus obrigação condicional, são válidas ${ }^{15}$.

Essa passagem nos mostra claramente a tentativa do formalismo de abstrair os conteúdos morais do discurso ético com a ideia de que para a possibilidade da universalização das máximas fosse imprescindível que não houvesse distinções qualitativas no raciocínio prático. Charles Taylor mostra com clareza que o formalismo é amplamente reducionista pelo fato "dessas linguagens de contraste qualitativo se tornarem marginalizadas, ou mesmo extinguidas completamente"16 do discurso moral. Ao extingui-las, os agentes morais deixam de ser agentes efetivamente para se tornarem atrelados irrestritamente as obrigações do chamado dever kantiano. Taylor diz contundentemente: "eu quero argumentar, em oposição a isso, que elas [as linguagens de contraste qualitativo] são centrais para o nosso pensamento moral e inerradicáveis dele"17.

O seu intuito é ultrapassar a visão formalista de que é possível "conseguir reduzir estes

\footnotetext{
${ }^{15}$ Cf. TAYLOR, Charles. The diversity of goods, in Philosophy and the human sciences - Philosophical papers 2. Cambridge: Cambridge University Press, 1985 p. 231. (Tradução nossa)

${ }^{16}$ Cf. TAYLOR, Charles. The diversity of goods, in Philosophy and the human sciences - Philosophical papers 2. Cambridge: Cambridge University Press, 1985 p. 234. (Tradução nossa). A respeito da importância das distinções qualitativas na ontologia moral, ver também: TAYLOR, Charles. What is human agency?, in Human Agency and Language - Philosophical papers 1. Cambridge: Cambridge University Press, 1985; e a Parte I de: TAYLOR, Charles. As Fontes do Self: a construção da identidade moderna. $3^{\mathrm{a}}$. ed. São Paulo: Loyola, 2011.

${ }^{17}$ Cf. TAYLOR, Charles. The diversity of goods, in Philosophy and the human sciences - Philosophical papers 2. Cambridge: Cambridge University Press, 1985, p. 234. (Tradução nossa)
}

\begin{tabular}{|c|c|c|c|c|c|}
\hline intuitio & $\begin{array}{c}\text { ISSN } \\
1983-4012\end{array}$ & Porto Alegre & Vol.7 - $\mathrm{N}^{\mathrm{o}} .1$ & $\begin{array}{l}\text { Junho } \\
2014\end{array}$ & p. $200-214$ \\
\hline
\end{tabular}


Um novo modelo de raciocínio prático como uma possível resposta ao fenômeno do multiculturalismo em Charles Taylor contrastes à irrelevância; o raciocínio ético pode manipulá-los através de um procedimento para determinar o que é certo que não os levem em consideração, ou os deixem meramente como preferências subjetivas, e, portanto, não se exige julgar seus méritos substantivos"18. A ultrapassagem desse momento Taylor mostra ser uma árdua tarefa, pois estamos enraizados nessas concepções distorcidas do raciocínio prático que nivelam e reduzem o ser humano a um profundo desengajamento com o mundo. Para ele:

As teorias formalistas alcançam sua plausibilidade devido ao fato delas estarem baseadas em certas intuições morais que são quase incontestáveis na sociedade moderna, baseadas como elas estão em certas precondições do próprio discurso moral combinado com uma tese sobre a homogeneidade racial de humanidade que é muito difícil desafiar em uma cultura contemporânea científica, não paroquial e historicamente sensitiva ${ }^{19}$.

Para finalizar, pode-se afirmar que esses dois modelos representam uma base comum das teorias éticas contemporâneas e que ser um filósofo moral na contemporaneidade sem estabelecer um diálogo com esses dois modelos-chave seria um grande equívoco. Não estenderemos mais nessa discussão, nosso intuito aqui foi apenas delinear como a tradição epistemológica com a sua visão representacionista, fundacionista e mecanicista do conhecimento influenciou os modelos de razão prática que se sucederam. Além do mais, a nossa intenção foi deixar claro que "uma das mais potentes raízes do ceticismo e do subjetivismo modernos no tocante à ética é o espírito naturalista do pensamento moderno"20.

\section{Para uma ontologia moral: Uma nova visão de raciocínio prático}

A tese defendida pelo nosso autor é a de que nós somos naturalmente seres que se autointerpretam e se autoavaliam, nesse movimento de autoconhecimento o homem está sempre em busca de sentido e configurando sua própria identidade. Adotando essa concepção, podemos dizer que o que nos diferencia das outras espécies para Taylor, é a nossa capacidade de avaliar nossos desejos, de ponderar previamente acerca das nossas escolhas. Nesse movimento propriamente humano, somos capazes de avaliar forte e fracamente.

Não obstante, segundo Taylor, a conquista da racionalidade moderna tem nos impulsionado por avaliar fracamente, temos sentido necessidade de dominar os resultados de

${ }^{18}$ Cf. TAYLOR, Charles. The diversity of goods, in Philosophy and the human sciences - Philosophical papers 2. Cambridge: Cambridge University Press, 1985, p. 240. (Tradução nossa)

${ }^{19}$ Cf. TAYLOR, Charles. The diversity of goods, in Philosophy and the human sciences - Philosophical papers 2. Cambridge: Cambridge University Press, 1985, p. 241 (Tradução nossa)

${ }^{20}$ TAYLOR, Charles. Explicação e Razão Prática. Argumentos filosóficos. São Paulo: Loyola, 2000, p. 52.

\begin{tabular}{|c|c|c|c|c|c|}
\hline intuitio & $\begin{array}{c}\text { ISSN } \\
1983-4012\end{array}$ & Porto Alegre & Vol.7 - $\mathrm{N}^{\mathrm{o}} .1$ & $\begin{array}{l}\text { Junho } \\
2014\end{array}$ & p. $200-214$ \\
\hline
\end{tabular}


Um novo modelo de raciocínio prático como uma possível resposta ao fenômeno do multiculturalismo em Charles Taylor nossas ações sem nos engajarmos em determinados desejos, sem sermos movidos por eles e pelos bens fundamentais. Essas características foram contribuições inegáveis da visão naturalista da realidade, visão essa que tendia ao desengajamento e à frieza da razão. Taylor pondera ainda que "nesse tipo de naturalismo, geralmente nos deparamos com uma admiração pelo poder da razão fria, desengajada, capaz de contemplar o mundo e a vida humana sem ilusão e de agir com lucidez para o melhor no interesse do florescimento humano"21.

Consoante Taylor, "a mente racional deve se abrir para algo mais profundo e mais pleno. Isto é algo interno; são nossos próprios sentimentos ou instintos mais profundos. Devemos, portanto, sanar a ruptura dentro de nós criada pela razão desengajada ao situar o pensamento em oposição ao sentimento, ao instinto ou à intuição"22. Essa afirmação de Taylor, remete-nos a uma tese já sustentada por ele de que as avaliações fracas que estão atreladas aos resultados das ações e, portanto, desengajadas, não são capazes de nos florescer em humanidade, pois somos seres de avaliações fortes, que nos interessamos pela qualidade das motivações, que procuram avaliar e decidir por bens de vida, bens hierarquicamente superiores aos bens comuns. Essa noção de superioridade de bens, que há bens de vida considerados imprescindíveis, é chamada por Taylor de hiperbens.

Nesse sentido, podemos afirmar que uma ética que prioriza a constituição do próprio indivíduo e que visa o bem é capaz de nos dar uma diretriz maior acerca de quem nós somos e de quem o outro é, ou seja, é capaz de culminar em uma política do reconhecimento eficaz. A nossa ideia principal é a de que sendo um avaliador forte, nós somos movidos existencialmente com mais profundidade do que como avaliador fraco, possibilitando-nos ser uma pessoa mais articulada e engajada.

Nessa perspectiva, pode-se dizer que a proposta de uma ética constitutiva em Charles Taylor está essencialmente relacionada com as breves categorias explicitadas acima. Em Taylor, não há uma separação entre aquilo que é do agente moral e aquilo que é do Self, pois a identidade e o bem estão inextrincavelmente entrelaçados. Assim sendo, faz-se necessário apontar a noção de razão prática adotada por ele frente às doutrinas éticas contemporâneas, que ainda estão muito vinculadas com uma visão naturalista do sujeito.

Charles Taylor, ao delinear um conceito de razão prática e fazer uma dura crítica às éticas procedimentalistas, mostra o problema dos critérios quando o problema são os desacordos morais como um dos problemas centrais do pluralismo de teorias éticas contemporâneas. Segundo ele, o modelo apodítico de raciocínio prático tende a resolver esses desacordos baseados em uma noção

${ }^{21}$ TAYLOR, Charles. Uma era secular. São Leopoldo: Unisinos, 2010, p. 23.

${ }^{22}$ TAYLOR, Charles. Uma era secular. São Leopoldo: Unisinos, 2010, p. 23.

\begin{tabular}{|c|c|l|l|l|l|}
\hline intuitio & $\begin{array}{c}\text { ISSN } \\
1983-4012\end{array}$ & Porto Alegre & Vol.7 $-\mathrm{N}^{\circ} .1$ & $\begin{array}{c}\text { Junho } \\
2014\end{array}$ & p.200-214 \\
\hline
\end{tabular}


Um novo modelo de raciocínio prático como uma possível resposta ao fenômeno do multiculturalismo em Charles Taylor fundacionista e, portanto, buscando critérios para um acordo. "É comum que estes proporcionam um padrão exteriormente definido com relação ao qual devemos avaliar independentemente cada teoria"23. Não obstante, para Taylor:

O problema está no pressuposto completamente irrefletido de que "critérios" nesse sentido são aquilo de que a discussão precisa. Veremos, ao examiná-lo de modo mais profundo, que esse pressuposto, tal como costumeiramente entendido no contexto do fundacionalismo, equivale a deixar de fora as formas mais relevantes e frutuosas da modalidade ad hominem ${ }^{24}$.

Taylor propõe, portanto, uma nova abordagem de razão prática onde a questão dos critérios, assim como o modelo apodítico admite, não poderá mais ser sustentada. Além do mais, ele defende que "a noção canônica, de cunho fundacionalista de arbitrar disputas por meio de critérios produz ceticismo em face da razão, desaparecendo uma vez que se perceba que costumamos discutir acerca das transições" 25 . Segundo ele:

O modelo ruim de raciocínio prático, fundamentado na tradição epistemológica, leva-nos constantemente a desconfiar das discussões de transição. Ele quer que busquemos "critérios" para decidir a questão, isto é, algumas considerações que possam ser estabelecidas mesmo fora das perspectivas em disputa e que, ainda assim, fossem decisivas, mas não pode haver considerações desse tipo. Minha perspectiva é definida pelas intuições morais que tenho, por aquilo que me move moralmente. Se abstraio disso, torno-me incapaz de compreender qualquer argumento moral. Só é possível me convencer mudando minha leitura de minha experiência moral e, em particular, minha leitura de minha história de vida, das transições por que passei - ou talvez recusei-me a passar ${ }^{26}$.

Logo, sua defesa é de que "o raciocínio prático é um raciocínio de transições"27. Para evidenciar tal afirmação, Taylor exemplifica a transição do período pré-galileano ao período da ciência moderna, tal transição gerou mudanças incomensuráveis em relação ao progresso tecnológico, por exemplo, nisso estamos convictos e seria um absurdo negar de que tenha sido um ganho epistêmico histórico. Não obstante, esse raciocínio de transições "visa estabelecer não que uma posição seja absolutamente correta, mas que alguma posição é superior a outra, cuja transição produz uma redução dos erros" 28 . Taylor evidencia sua posição, portanto:

\footnotetext{
${ }^{23}$ TAYLOR, Charles. Explicação e Razão Prática. Argumentos filosóficos. São Paulo: Loyola, 2000, p. 55.

${ }^{24}$ Cf. TAYLOR, Charles. Explicação e Razão Prática. Argumentos filosóficos. São Paulo: Loyola, 2000, p. 55.

${ }^{25}$ Cf. TAYLOR, Charles. Explicação e Razão Prática. Argumentos filosóficos. São Paulo: Loyola, 2000, pp. 60-61

${ }^{26}$ TAYLOR, Charles. As fontes do Self: A construção da identidade moderna. $3^{\mathrm{a}}$ ed. São Paulo: 2011, p. 102.

${ }^{27}$ Cf. TAYLOR, Charles. As fontes do Self: A construção da identidade moderna. $3^{\mathrm{a}}$ ed. São Paulo: 2011, p. 101.

${ }^{28}$ Cf. TAYLOR, Charles. As fontes do Self: A construção da identidade moderna. $3^{\mathrm{a}}$ ed. São Paulo: 2011, p.
}

\begin{tabular}{|c|c|l|l|l|l|}
\hline intuitio & $\begin{array}{c}\text { ISSN } \\
1983-4012\end{array}$ & Porto Alegre & Vol.7 $-\mathrm{N}^{\circ} .1$ & $\begin{array}{c}\text { Junho } \\
2014\end{array}$ & p.200-214 \\
\hline
\end{tabular}


Um novo modelo de raciocínio prático como uma possível resposta ao fenômeno do multiculturalismo em Charles Taylor Essa é, a meu ver, a forma mais comum de raciocínio prático de vida; nela, propomos a nossos interlocutores transições mediadas por movimentos redutores de erros, seja por meio da identificação de contradições, da dissipação da confusão ou resgatando do desprezo (em geral motivado) uma consideração cuja significação eles não podem contestar. Mas essa é uma forma de argumento em que o apelo a critérios, ou mesmo ao desempenho diferencial de concepções rivais com respeito a alguma consideração decisiva, está bastante fora de questão. Aqui, a modalidade de argumento ad hominem alcança seu nível mais intenso e produtivo ${ }^{29}$.

Para sustentar a nossa tese, algumas perguntas nortearão o nosso trabalho: "Como então é feito o raciocínio moral? De que maneira convencemos racionalmente os outros ou a nós mesmos? Haverá algum modo racional de A convencer B de que sua perspectiva do hiperbem é superior? E, caso contrário, como A pode convencer racionalmente a si mesmo? Ou tudo não passa de uma questão de intuições e sensações sub-racionais (como os naturalistas vêm alegando desde sempre)?"30 Como podemos dar razões para as nossas escolhas de hiperbens em relação a outras culturas que não participam do mesmo quadro moral cultural? É possível defender superioridade de hiperbens interculturalmente? Como dar razões dispensando a noção de critérios, próprios do modelo de raciocínio apodítico?

Não intentamos responder todas essas questões aqui, nem sabemos se seríamos capazes disso, mas para delinear realmente a proposta de Taylor a colocação destas faz-se necessária. Nesse ponto, é importante frisar que a separação entre a explicação e a razão prática é um ponto central para a concepção que estamos adotando aqui. O modo de compreensão humana em que se fundou a tradição platônico-aristotélica mostra que "somos todos capazes de entender as coisas em termos de seu lugar numa ordem significativa"31. Somente esse tipo de compreensão unifica explicação e razão prática. Não obstante, a revolução científica do século XVII, com a visão de um universo neutro, tende a estabelecer uma "separação entre a explicação e a razão prática" 32 p. 58. Essa separação nos levou a perder a visão de ordem significativa e de um lugar no cosmos que a ciência pré-galileana tinha como fundamento:

Esta operava num paradigma de compreensão distinto, paradigma para o qual a capacidade de manipulação é irrelevante, e que mostra sua validade em termos de outra capacidade, a de descobrir nosso lugar adequado no cosmos e em encontrar a conformidade com esse cosmos. E, poder-se-ia alegar, a civilização

101.

${ }^{29}$ Cf. TAYLOR, Charles. As fontes do Self: A construção da identidade moderna. $3^{\mathrm{a}}$ ed. São Paulo: 2011,. p. 66.

${ }^{30}$ Cf. TAYLOR, Charles. As fontes do Self: A construção da identidade moderna. $3^{\mathrm{a}}$ ed. São Paulo: 2011, pp. 100-101.

${ }^{31}$ TAYLOR, Charles. Explicação e Razão Prática. Argumentos filosóficos. São Paulo: Loyola, 2000, p. 58.

${ }^{32}$ Cf. TAYLOR, Charles. Explicação e Razão Prática. Argumentos filosóficos. São Paulo: Loyola, 2000, p. 58.

\begin{tabular}{|c|c|c|c|c|c|}
\hline intuitio & $\begin{array}{c}\text { ISSN } \\
1983-4012\end{array}$ & Porto Alegre & Vol.7 - $\mathrm{N}^{\mathrm{o}} .1$ & $\begin{array}{l}\text { Junho } \\
2014\end{array}$ & p. $200-214$ \\
\hline
\end{tabular}


Um novo modelo de raciocínio prático como uma possível resposta ao fenômeno do multiculturalismo em Charles Taylor tecnológica moderna fracassa espetacularmente nisso $^{33}$.

Dessa passagem podemos deduzir que toda a defesa de Taylor será a reunificação da explicação e da razão prática. Justamente para ressignificar o lugar do cosmos que perdemos. É a partir dessa objetificação do mundo e de si mesmo que instauramos um universo "desencantado", compreendendo-o como mero mecanismo, despido de qualquer essência espiritual ou dimensão expressiva $^{34}$. Nessa tentativa de neutralizarmos tudo, de entendermos o mundo matematicamente, "desmistificamos o cosmo como organizador de fins" ${ }^{135}$. Como Koyré expressou muito bem. A revolução científica e espiritual do século dezessete levou:

O homem, como às vezes se diz, a perder seu lugar no mundo, ou, dito talvez mais corretamente, a perder o próprio mundo em que vivia e sobre o qual pensava, e ter de transformar e substituir não só seus conceitos e atributos fundamentais, mas até mesmo o quadro de referência de seu pensamento ${ }^{36}$.

Para finalizar, defendemos que o esforço de Taylor é por uma ética da articulação rompendo com um conceito errôneo de razão prática em que a falibilidade dos critérios tem gerado um descrédito da razão e, por conseguinte, um ceticismo moral. "Boa parte da filosofia moral naturalista procura livrar-se de vez dessas distinções, não dar lugar na vida moral a um sentido dos bens incomparavelmente superiores ou hiperbens" ${ }^{37}$. Esse ato nos conduz a uma reflexão apurada sobre o modo de lidar com a vida, sobre a identidade do Self, sobre essa crise ética que se instaura e tem entrado na sociedade por forma de mal-estar.

Afinal, a constatação de uma crise ética é o momento ideal para se rediscutir um novo modelo de razão prática e mostrar as insuficiências do modelo desengajado e instrumental atual, profundamente influenciado por concepções naturalistas e utilitaristas aparentemente tão arraigadas no sujeito contemporâneo. Dessa constatação, Taylor diz que a possível causa desse sentimento de descordo moral talvez seja pelo fato de as atuais teorias éticas terem priorizado "mais o que é certo a fazer do que é bom ser"38. Nosso esforço foi mostrar que somos configurados por certas categorias inescapáveis, que vivemos em um espaço moral e, portanto,

${ }^{33}$ Cf. TAYLOR, Charles. Explicação e Razão Prática. Argumentos filosóficos. São Paulo: Loyola, 2000, p. 59.

${ }^{34}$ TAYLOR, Charles. As fontes do Self: A construção da identidade moderna. $3^{\mathrm{a}}$ ed. São Paulo: 2011, p. 193.

${ }^{35}$ Cf. TAYLOR, Charles. As fontes do Self: A construção da identidade moderna. $3^{\mathrm{a}}$ ed. São Paulo: 2011, p. 197.

${ }^{36}$ KOYRÉ, ALEXANDRE. Do mundo fechado ao universo infinito. $4^{\text {a }}$. ed. Rio de Janeiro: Forense universitária, 2006, pp. 5-6.

${ }^{37}$ TAYLOR, Charles. As fontes do Self: A construção da identidade moderna. $3^{\mathrm{a}}$ ed. São Paulo: 2011, p. 109.

${ }^{38}$ Cf. TAYLOR, Charles. As fontes do Self: A construção da identidade moderna. $3^{\mathrm{a}}$ ed. São Paulo: 2011, p. 15.

\begin{tabular}{|c|c|c|c|c|c|}
\hline intuitio & $\begin{array}{c}\text { ISSN } \\
1983-4012\end{array}$ & Porto Alegre & Vol.7 - $\mathrm{N}^{\mathrm{o}} .1$ & $\begin{array}{l}\text { Junho } \\
2014\end{array}$ & p. $200-214$ \\
\hline
\end{tabular}


Um novo modelo de raciocínio prático como uma possível resposta ao fenômeno do multiculturalismo em Charles Taylor

defender um modelo substantivo de razão prática.

\section{Multiculturalismo e reconhecimento: Aplicação desse novo modelo de razão prática}

O fenômeno do multiculturalismo tem sido um dos problemas mais característicos de nossa era, principalmente em relação à proliferação de políticas públicas que busquem promover o reconhecimento entre culturas. Pode-se perceber que o que diz respeito ao debate, muitas teorias tem ganhado espaço, não obstante a aplicabilidade das mesmas tem se mostrado profundamente difícil, pois a prioridade e a adesão a doutrinas liberalistas e, portanto, de defesa do universalismo e da igualdade, tem se mostrado cada vez mais insatisfatória. É nesse contexto de pluralismo seja político, cultural e teórico que a proposta de Taylor se insere. Nessa última e terceira parte, intentamos mostrar, portanto, o quanto a racionalidade moderna tem subjugado outros modos de racionalidade com os seus próprios padrões e promovido uma visão distorcida e inferiorizada de outras identidades devido a um reconhecimento errôneo. Consoante Taylor, "o reconhecimento incorreto não implica só uma falta do respeito devido. Pode também marcar as suas vítimas de forma cruel, subjugando-as através de um sentimento incapacitante de ódio contra elas mesmas. Por isso, o respeito devido não é um ato de gentileza para com os outros. É uma necessidade vital" 39 .

Percebe-se que o posicionamento de Taylor quanto ao problema do reconhecimento entre culturas e quanto ao aspecto monológico propagado pela civilização ocidental, profundamente etnocêntrica, é bastante claro. O intuito de Taylor é fazer jus às diferenças em face de uma cultura da igualdade, pois para ele deve haver uma articulação entre as identidades individuais e coletivas de tal forma que a identidade e o processo de reconhecimento andem lado a lado, afinal, não é possível que haja essa articulação de modo monológico como temos tentado manter na modernidade, por esse motivo Taylor pode ser considerado um forte crítico dessa atomização dos indivíduos e dos seres sociais, enquanto tal. A esse respeito, Taylor diz que "a modernidade tem tornado invisível um aspecto definitivo da condição humana que é o caráter fundamentalmente dialógico" ${ }^{40}$, toda a sua empreita será, portanto, um resgate pelo aspecto da dialogicidade diante dessa "tendência esmagadoramente monológica que tem caracterizado a filosofia moderna dominante"41.

39 TAYLOR, Charles. Multiculturalismo: Examinando a política de reconhecimento. Lisboa: Instituto Piaget, s.d. p. 46.

${ }^{40}$ Cf. TAYLOR, Charles. Multiculturalismo: Examinando a política de reconhecimento. Lisboa: Instituto Piaget, s.d., p. 52.

${ }^{41}$ Cf. TAYLOR, Charles. Multiculturalismo: Examinando a política de reconhecimento. Lisboa: Instituto Piaget, s.d., p. 52.

\begin{tabular}{|c|c|c|c|c|c|}
\hline intuitio & $\begin{array}{c}\text { ISSN } \\
1983-4012\end{array}$ & Porto Alegre & Vol.7 - $\mathrm{N}^{\mathrm{o}} .1$ & $\begin{array}{l}\text { Junho } \\
2014\end{array}$ & p. $200-214$ \\
\hline
\end{tabular}


Um novo modelo de raciocínio prático como uma possível resposta ao fenômeno do multiculturalismo em Charles Taylor

Para iniciar a nossa discussão acerca do multiculturalismo e dos problemas morais advindos desse fenômeno, faz-se necessário compreender como o homem ocidental tem interpretado a própria racionalidade e como esse modelo tem se mostrado profundamente etnocêntrico e negligenciado outras formas de saber ético e de racionalidades. Taylor em seu artigo intitulado Rationality nos mostra o quanto estamos equivocados ao vermos as outras culturas de um modo hierárquico e não de acolhida, que implicaria em um tipo de reconhecimento da igualdade que também priorizaria as idiossincrasias de cada cultura. Taylor inicia a discussão com alguns importantes questionamentos, a saber, "há padrões de racionalidade que são válidos para outras culturas? Nós podemos afirmar que, por exemplo, as pessoas da cultura pré-científica que acreditavam, deixe-nos dizer, em feitiçaria ou mágica são menos racionais do que nós somos? Ou pelo menos que suas crenças são menos racionais?" 42.

Essas perguntas direcionam bem a nossa pesquisa, a nossa tendência ao etnocentrismo não é um problema novo, mas marca da nossa postura teorética diante da vida e da nossa depreciação diante de culturas que adotam outras posturas, que sejam ateoréticas, por exemplo. Nós incorporamos, principalmente na modernidade com a noção de desengajamento, a ideia de que tudo que diz respeito aos nossos desejos, as nossas escolhas não são conteúdos racionais e não podem ser considerados práticas morais.

Nessa perspectiva de desengajamento e de neutralidade, a noção de uma política da igualdade tornou-se não só evidente, mas irrevogável na modernidade. O ideal propagado de dignidade, que deu lugar à noção de honra das sociedades do passado, passou a ser a marca das sociedades democráticas modernas, afinal a igualdade entre todos os seres humanos passou a ser uma característica basilar da nossa era.

Não obstante, essa tendência tem se mostrado fonte de vários problemas, principalmente em relação ao reconhecimento de culturas minoritárias. Segundo Taylor, o liberalismo político propagado por esse ideal não tem feito jus à noção de que todos são realmente dignos de serem reconhecidos, não somente no que tange à igualdade, mas às diferenças, às diversas identidades individuais e coletivas. Por isso, ele ressalta que "o que a idade moderna tem de novo não é a necessidade de reconhecimento, mas sim as condições que podem levar a tentativa de reconhecimento ao fracasso"43. Nesse sentido, a nossa defesa é de uma política que reconhece a igualdade e as diferenças simultaneamente, ou seja, o reconhecimento da dignidade e da autenticidade de cada cultura de modo articulado.

${ }^{42}$ TAYLOR, Charles. Rationality, in Philosophy and the human sciences - Philosophical papers 2. Cambridge: Cambridge University Press, 1985, p. 134-135. (Tradução nossa)

${ }^{43}$ TAYLOR, Charles. Multiculturalismo: Examinando a política de reconhecimento. Lisboa: Instituto Piaget, s.d. p. 55.

\begin{tabular}{|c|c|l|l|l|l|}
\hline intuitio & $\begin{array}{c}\text { ISSN } \\
1983-4012\end{array}$ & Porto Alegre & Vol.7 $-\mathrm{N}^{\circ} .1$ & $\begin{array}{c}\text { Junho } \\
2014\end{array}$ & p.200-214 \\
\hline
\end{tabular}


Um novo modelo de raciocínio prático como uma possível resposta ao fenômeno do multiculturalismo em Charles Taylor

Essa não é uma tarefa nada simples nem nova, nosso intuito não é simplificá-la nem resolvê-la, mas sim mostrar que um percurso para o reconhecimento saudável é possível desde que tenhamos em mente um modelo de raciocínio prático voltado não para a hegemonia da racionalidade moderna e das civilizações ocidentais, mas para a dialogicidade como uma categoria inalienável do ser humano. Com essa noção de dialogicidade, Taylor integra à sua política do reconhecimento a ideia gadameriana de fusão de horizontes. Com essa concepção "aprendemos a movimentar-nos num horizonte mais alargado, dentro do qual partimos já do princípio de que aquilo que serve de base à valorização pode ser considerado como uma possibilidade a par do background da cultura que antes nos era desconhecida" 44 . Essa perspectiva nos leva à concepção de Taylor de critérios pré-determinados de que falamos na segunda parte, pois para ele devemos estar abertos às transformações de nossos critérios para entender o outro, para a interpretação que o outro faz de si mesmo a partir de sua própria cultura e uma ontologia que se preze deve estar consciente de que a adoção de critérios de juízo tem sido o grande equívoco do debate que se insere o multiculturalismo.

Para finalizar, gostaríamos de defender a tese de que o modelo de raciocínio prático de Taylor ao priorizar como conteúdo moral as nossas distinções qualitativas e as nossas escolhas pelo bem pode ser um caminho de superação do etnocentrismo propagado pela nossa civilização e de substantivação da vida ética.

\section{Conclusão}

A conclusão que chegamos aqui não é determinista, se o fosse entraríamos em contradição com a nossa tese fundamental, o fato é que o caminho proposto desse novo modelo de raciocínio prático como resposta ao problema do multiculturalismo é árduo, mas necessário e não será realizado sob a pena de um filósofo. $\mathrm{O}$ nosso intuito aqui foi reivindicar por uma concepção de self e de cultura mais alargada do que aquela que o liberalismo procedimental tem proposto. $\mathrm{O}$ caminho pode ser traçado, portanto, a partir da articulação fundamental entre reconhecimento e identidade, entre antropologia e razão prática, entre indivíduo e sociedade, que Taylor tem buscado sabiamente conciliar.

\section{Referências}

${ }^{44}$ Cf. TAYLOR, Charles. Multiculturalismo: Examinando a política de reconhecimento. Lisboa: Instituto Piaget, s.d., p. 88.

\begin{tabular}{|c|c|l|l|l|l|}
\hline intuitio & $\begin{array}{c}\text { ISSN } \\
1983-4012\end{array}$ & Porto Alegre & Vol.7 $-\mathrm{N}^{\mathrm{o}} .1$ & $\begin{array}{c}\text { Junho } \\
2014\end{array}$ & p.200-214 \\
\hline
\end{tabular}


Um novo modelo de raciocínio prático como uma possível resposta ao fenômeno do multiculturalismo em Charles Taylor

FRANKFURT, Harry. Freedom of the will and the concept of a person, in The Journal of Philosophy, Vol. 68. N. 1 (1971), pp. 5-20.

KOYRÉ, ALEXANDRE. Do mundo fechado ao universo infinito. $4^{\mathrm{a}}$. ed. Rio de Janeiro: Forense universitária, 2006.

RIBEIRO, Elton Vitoriano. Reconhecimento ético e virtudes. São Paulo: Loyola, 2012.

RORTY, Richard. A filosofia e o espelho da natureza. Rio de Janeiro: Relume Dumará, 1995.

TAYLOR, Charles. Argumentos filosóficos. São Paulo: Loyola, 2000.

. As Fontes do Self: a construção da identidade moderna. $3^{\text {a }}$. ed. São Paulo: Loyola, 2011.

Press, 1985

Philosophy and the human sciences - Philosophical papers 2. Cambridge: Cambridge University

. Human agency and language - Philosophical papers 1. Cambridge: Cambridge University Press, 1985.

. La Libertad de los modernos. Buenos Aires: Amorrortu, 2005.

. Leading a Life, in Chang, R. (org.), Incommensurability, Incomparability and Practical Reason, Cambridge, 1997, 170-183.

. Multiculturalismo: Examinando a política de reconhecimento. Lisboa: Instituto Piaget, s.d. . Uma era secular. São Leopoldo: Unisinos, 2010.

Recebido em: 25/05/2014

Aprovado para publicação: 01/06/2014

\begin{tabular}{|c|c|c|c|c|c|}
\hline intuitio & $\begin{array}{c}\text { ISSN } \\
1983-4012\end{array}$ & Porto Alegre & Vol.7 - $\mathrm{N}^{\mathrm{o}} .1$ & $\begin{array}{l}\text { Junho } \\
2014\end{array}$ & p. $200-214$ \\
\hline
\end{tabular}

